\title{
DECOLONISING THE CURRICULUM; DECOLONISING OURSELVES. WORKING TOWARDS RESTORATION THROUGH TEACHING, LEARNING AND PRACTICE
}

\author{
BY ANTONIA HENDRICK AND SUSAN YOUNG
}

\section{ABSTRACT}

Using the idea of 'Ally Work' as non-indigenous social work educators working predominantly with non-indigenous students, we have constructed a framework to assist our teaching and learning. The 'Ally' framework helps us to articulate some of the practices of recognition, reconciliation and restoration and to encourage their use by our non-indigenous students when they are working with Aboriginal and Torres Strait Islander peoples. This is part of a larger project of decolonising the curriculum in our separate institutions in Western Australia, and we illustrate these practices from our experiences inside and outside the classroom.

\section{INTRODUCTION}

We address this work directly to the concepts of recognition, reconciliation and restoration to frame the work we call 'Ally Work'. This application emerges from engagement at the Fourth Indigenous Voices Conference in Social Work held in Alta, Norway, in 2017 from which there has been interest in the practices associated with recognition, reconciliation and restoration. We acknowledge those who have gone before us, who have examined and worked with these concepts and practices, especially indigenous scholars and practitioners. We use these concepts to help us develop further the framework for our practice as social work educators 
and practitioners at two different universities in Western Australia. Neither of us are indigenous people and we, along with our students, work with indigenous people, predominantly Aboriginal and Torres Strait Islander peoples in Western Australia. We conceptualise this framework as ethical practice and describe how we understand its connection to the practices of recognition, reconciliation and restoration through our teaching and learning, particularly by identifying some of the outcomes we have witnessed in and outside of the classroom. We conclude with some reflections of how we consider Ally Work may help to contribute to an ongoing project of decolonisation of social work education.

\section{ALLY WORK AS ETHICAL PRACTICE}

We consider the practice of Ally Work to be informed by the inseparability of ethics as self-rule (Foucault in Bay, 2014, p.40) and a process of self-formation (Critchley in Bay, 2014, p.41). This we have framed in the following Figure 1. to illustrate the individual, relational and public action elements of Ally work which make ethical demands of us as individuals, in relationship with others and in the public societal sphere. So in this sense, this work has applicability across areas of practice not simply with Aboriginal and Torres Strait Islander peoples - although the distinction and our duty is to act politically (with self-rule) to challenge broader systems of oppression since colonisation.

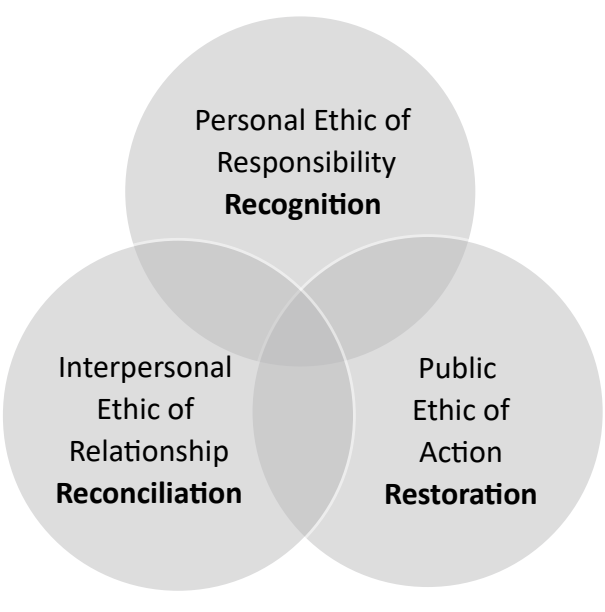

Figure 1. The ethics of Ally Work 
Ethical enactment in the indigenous and colonised worlds requires that social work educators revisit previous formulations of how non-indigenous people engage with indigenous people using multiculturalist or postcolonial and/or decolonising theorising to ensure that the work that is done, is responsive to the needs and desires of indigenous people. We illustrate how we understand these ethical imperatives through an examination of conceptualisations of recognition, reconciliation and restoration.

\section{CONCEPTUALISING RECOGNITION, RECONCILIATION AND RESTORATION FOR ALLY WORK}

Recognition, reconciliation and restoration are concepts that are differentially defined and applied by authors and across contexts. Our purpose is not to examine these differences, but rather conceive of them as aspects of Ally work and ethical practice. Recognition, reconciliation and restoration, for us then, are larger than individual acts, and how individuals engage with them and their underpinning principles will contribute to their overall enactment in the public arena. Actions in the public sphere are no more than systematised or collective activities of individuals, often, but not only, imbued with formal roles, as in the case of policy making. Rather than reifying systems as somehow external to their human agents, or deflecting the personal responsibilities which should be considered in the important tasks of policy decision making and distancing them from the people making those decisions, the public sphere is a place or each of us to connect with and influence. Each of us has a role to play and these roles demand action in our individual, group, organisational and policy encounters. Hence we have conceptualised this work as the inter-linkages between the concepts as displayed above. We will provide examples of how these linkages are designed for and used in the teaching/learning environment later in the chapter. But here we present the principles underpinning them. We accept that the personal is the political and that Recognition, Reconciliation and Restoration are interconnected. We also reiterate that the policy and organisational settings are those in which individual actors occupy and act from formal roles. Our definition of Decoloniality (Hendrick \& Young, 2018) following Maldonado-Torres (2016), offers us a way to expand Ally practices to examine how the project of recognition, reconciliation and restoration may be progressed as decolonial practice in teaching and learning. 


\section{RECOGNITION}

Recognition is a foundational ethical principle which describes the 'process of social and political transformation that promotes a new ethics of relationality that is grounded in reparative practices of love towards the Other' (Zembylas, 2018). Citing Figueroa, Zembylas (2018) reminds us of how colonial violence dehumanises. The ethical project then includes recognition by the colonisers of the violence perpetrated against Aboriginal and Torres Strait Islander peoples. In a settler country such as Australia, all of us who are not indigenous benefit disproportionally from the colonising project. While we accept that identity is multifaceted, we also take the view that in Australia, Aboriginal and Torres Strait Islander peoples are the First Nations peoples who suffered the dispossession of their land and sovereignty on the landing of the British First Fleet. Only latterly did the fiction started then of Terra Nullius, or land belonging to no one, been reversed. But the colonial systems and structures largely remain. These are very familiar to those of us who have inherited our identities from Great Britain and we derive collective although not uniform benefits from their existence. As long as these structures and systems remain intact, even though they do not serve all people equally, especially many newcomers from culturally and linguistically diverse lands, they serve the First Nations people even less equally and equitably. As long ago as 1994 Bhabha (1994) criticised the binary of coloniser-colonised. The effects of a colonising project on a colonised people however continue, even while identities become more fluid and cultures hybrid. The complexities attendant on changing and merging identities and cultures in the context of the relationships between Australia's indigenous peoples and other Australians are themselves worthy of a separate chapter and will not be discussed here, save to note the problematics of binary allocations inherent in notions of the coloniser and the colonised. In adopting an Ally framework, we seek to apply Zembylas' principle of relationality while remaining cognisant that binaries will continue to lurk under even the most well intentioned aims.

Recognitive practice requires the individual, whether individual worker, manager or policy maker, to accept individual or personal responsibility for the following precepts: acknowledgment and adherence to ensuring that to work with indigenous knowledges, practices and culture, indigenous ownership is paramount. Permission must be sought for their use. Indigenous peoples have 
the inalienable right to self-definition, and individuals need to resist appropriation, particularly of knowledge, but also of other cultural artefacts without permission. The acts of recognition include individual self-recognition, that is, the conscious investigation of and critical reflection of the 'self' who is doing the work, with its values, beliefs and experiences. Realisation of unearned privilege is a crucial step here. Relating with recognition is, among other considerations, to understand that definitions of self and the environment should not be imposed and that Aboriginal and Torres Strait Islander peoples have the right to define how they view their identity, their family and community structures and ways of being in the world.

Acting responsibly with recognition is to continue to advocate for inclusive or alternate policies and practices which do not, as often occurs, have the effect of exclusion. The low employment rate in certain workplaces, citing the lack of formal qualifications, is one example and a reason for the introduction of affirmative action strategies, against which, however, there continues to be opposition (see, for example Chow \& Knowles, 2015). This example is illustrative here. An indigenous unit taught across practice disciplines in one of our universities, was initially taught by a local Aboriginal person, who happened to be one of very few local Aboriginal people with a $\mathrm{PhD}$. When that lecturer left, the selected replacement sought was for a person, preferably Aboriginal, with a $\mathrm{PhD}$. This excluded the many appropriate people with the cultural knowledge, skills and experiences who teach into the unit and support its existence in the wider community. Ultimately an indigenous lecturer took the role, but was unsupported and left some time later to work in a culturally supported academic role where there are more indigenous people. Constant attention to exclusionary, discriminatory and 'colour-blind' practices is needed. Another example is the tendency to construct indigenous people as clients only and not, say, managers. In the same unit mentioned above, some students from non-social work disciplines wondered why they were required to do the unit as they stated 'we are not going to work with Aboriginal people'. A lecturer in that unit pointed out to them that they may be working with Aboriginal people as colleagues - a proposition which surprised them.

The 1990s decade was a watershed in Aboriginal and Torres Strait Islander - non-indigenous relations in Australia; the recognitive process coincided with the release of the Aboriginal Deaths in Custody Report which reported on the deaths of 99 people across Australia in the 1980s. The discussion about a Treaty had concluded with the realisation that no Treaty was going to be 
enacted, to the disappointment of many Aboriginal and Torres Strait Islander peoples as well as the Prime Minister who championed it. The case Mabo and others versus Queensland (2) had been argued in the High Court to challenge the notion of Terra Nullius. Its lawyers this time were quietly confident, a confidence that was well-founded as shown by the decision the following year to reject the doctrine of Terra Nullius and accept Aboriginal and Torres Strait Islander peoples' prior occupation of firstly the Mer Islands in the Torres Strait and subsequently the mainland. While a very conservative and contained decision, this was fiercely opposed at legislative and public levels, but led the way to increased Aboriginal and Torres Strait Islander opportunities and inclusion. Much of this history is not known by students, to our surprise. Part of the teaching and learning activities therefore presents these events. Not only do the students themselves respond with some disbelief that they did not know this history, but also with some scepticism that it could not be as widespread or devastating as some of the works suggest. It is by listening to the lived experiences of people who had lived through that period as parents themselves or as removed children, that students start to realise the on-going effects of such events as the Stolen Generations, in which it was government policy, often enacted by social workers, to remove light-skinned children from their families in order to assimilate them into white society, a policy which has been subsequently termed 'cultural genocide' (Krieken, 1999) and a practice known as 'to smooth the dying pillow' (van den Berg, 2004, p.2). As Dudgeon and Pickett (2000, p.82) maintain 'At the very least, [reconciliation] is a reconciling to the past, which is not about just acknowledging the past history of invasion, settlement, and policies towards indigenous people, but recognising the impact of this history on indigenous people today.' Students learn directly from people who lived these experiences in person, preferably, and from podcasts and videos. This unit formed the background for the students in a later, more targeted project, which was highly valued by the small group of students who were able to participate.

Despite the many and continuing set-backs, there have been significant advances in Aboriginal and Torres Strait Islander - non-indigenous relations, with universities such as ours ensuring, for example and among other policy decisions, that all students are able to and in some cases required to be exposed to Aboriginal and Torres Strait Islander knowledges and ways of being, doing and knowing. What this has meant in practice has been the employment and engagement, as staff and guest lecturers, of Aboriginal and Torres Strait 
Islander peoples to ensure that cultural material is taught in culturally appropriate ways, even and especially when these staff do not meet the usual academic requirements for appointments.

Notwithstanding these developments, there is still an often tense and sometimes divisive policy debate as to how to recognise Australia's First Peoples. A recent example of many is the Recognise campaign, funded through the Reconciliation Council and defunded in 2017, without substantial progress towards Constitutional inclusion or even acknowledgement. How to recognise Aboriginal and Torres Strait Islander peoples and their place in Australia meets fierce opposition, the likely result being that the hoped for inclusion or acknowledgement of Australia's First Peoples in the Constitution will not occur, in this generation at least.

Our ethical obligations as lecturers require that, for ourselves, we not only accept the precepts of individual responsibility for recognition, with all that entails, but that we walk alongside our students as they grapple with what recognition means in practice. Ensuring that they have the opportunities for meaningful engagement with Aboriginal and Torres Strait Islander peoples and that they understand what is required of them as practitioners is a courselong endeavour. To do this we try to provide a teaching and learning environment in which Aboriginal and Torres Strait Islander peoples have a place and acknowledged status as expert knowledge holders; where we aspire to epistemological equality (Young, Zubrzycki, Bessarab, Green, Jones \& Stratton, 2013) as best as is possible within the academy, using Aboriginal and Torres Strait Islander pedagogies (Zubrzycki, Green, Jones, Stratton, Young \& Bessarab, 2014) to enable students to experience and understand that knowledges and practices have cultural specificities and value; and to develop appropriate and relevant responses in their interactions with Aboriginal and Torres Strait Islander peoples.

\section{RECONCILIATION}

As with many others, we conceptualise Reconciliation as relational (Gavrielides \& Artinopoulou, 2016; Lu, 2018; Nadler, 2012), rather than only in its structural form (Graeme \& Mandawe, 2017). The restoration of friendly relationships, a common understanding of the term, assumes a relationship on those terms existed in the past, when for most indigenous peoples, the 
practices and processes of colonisation were anything but. Another meaning refers to become accepting of one's fate, a perspective that is anathema to indigenous peoples. The advent around the world of Truth and Reconciliation Commissions brings new imperatives which require the oppressors to make some amends for the treatment meted out to those they oppressed, and includes the recognition referred to above, but at the same time requests that those oppressed peoples come to meet their oppressors half way (Truth and Reconciliation Commission, 1998) - a step too far for some. Nevertheless, a reconciliatory purpose is to find ways of working together and this is the purpose in our teaching and practice.

Again, there are actions which are appropriate at individual, organisational and policy levels, the most easily recognised in Australia being the Reconciliation Council established in 2001 to replace the Council for Aboriginal Reconciliation convened 10 years earlier. This process introduced the practice of Reconciliation Circles which introduced many Australians to previously unknown knowledge through structured interactions between Indigenous and non-Indigenous people, and more importantly to Aboriginal and Torres Strait Islander peoples, even though doubts existed as to how meaningful or long lasting this engagement was (Riggs, 2005). Aboriginal and Torres Strait Islander people daily walk in two worlds. But they walk in the white world on our terms not theirs. Much of their experience of that world has engendered mistrust and there remains distrust and lack of human personal relationships. In one of the teaching and learning projects in one of our universities, learning to trust wadjellas (whitefellas) was a big step for one of the Elders, and to form relationships she described as friendship.

Practices of reconciliation in the classroom must redress the past. Included in, but not restricted to these practices, are the following. Attending to the lack of historical knowledge and understanding without engendering guilt and shame among the audience is one strategy. Inviting non-Indigenous students to reflect on the consequences of colonisation on people and critically reflect on not only the practical results, such as parents brought up in institutions not having learnt parenting skills for their own children, is another. Modelling relationships between Aboriginal and Torres Strait Islander lecturers and their non-indigenous colleagues in respectful but essentially reversed positions indicates to students that they too will need to stand in such positions with Aboriginal and Torres Strait Islander people. Ownership of knowledge and cultural authority is demonstrated as having been re-located from what pre- 
viously was considered the norm. This reversal for students is important, as it indicates that the supposed 'expert' in the form of accepted Western knowledge (the Professor), is no expert in other epistemologies, but rather is repositioned as a learner. Repositioning Aboriginal and Torres Strait Islander peoples as experts also re-frames the usual pre-conception of them as only clients. Skills of communication across cultures may be demonstrated through these interactions, and importantly, also the skill of silence to closely listen and the skill of meticulous attention. We have both learnt to 'shut up and listen' from hard-won experience.

The ethical practices of reconciliation are essentially those of relationships and perhaps what Sandoval (2000) describes as 'decolonial love' to indicate non-indifference and responsibility. Maldonado-Torres (2008, p.187) invokes the notion of ally in his consideration of decolonnial love as alliances across difference. Yet not all Aboriginal and Torres Strait Islander peoples are willing to enter into or maintain relationships with non-indigenous people, with non-indigenous social workers in particular, or those from the academy, where there are still recollections of theft, appropriation and misrepresentation (Mulcock, 2007). Knowledge has been subjugated as well as contradictorily appropriated. Reconciliatory practice recognises that such theft, appropriation and misrepresentation has occurred and determines not to replicate it, instead committing to genuine relationships founded on trust and respect. These are not awarded lightly and we must earn them through our actions and interactions. Unlearning what we had previously taken as 'truth', seeking permission for access to knowledge, working with and not imposing external definitions of identity are all actions that are needed to be practiced. Offering to 'be' in relationships but at the same time understanding that these relationships may be refused is one of the more crucial lessons to be learned. Both Land (2015) and Bishop (2002) caution against expecting thanks for participation as an ally, noting that unity or friendship is not the goal. Indeed, actions of allies may be accepted, but ongoing relationships rejected.

\section{RESTORATION}

Closely aligned with reconciliation is the notion of restoration. As with reconciliation, Restoration has different conceptualisations and applications. Coupled with indigenous interests, restoration invokes an aim both to re(-)form rela- 
tionships that have been severed (reconcile) and to pursue genuine invitations for inclusion and to redress injustices (Absolon, 2016). This requirement to provide redress is both present in reconciliation understandings (a main focus for the Truth and Reconciliation Commissions) but also importantly permits relationships to be created, fostered and maintained founded on the genuine acceptance of prior and continuing wrongs and the determination they shall not go un-acknowledged. A common application for redress is in relation to structural components: self rule, societal order, rights, languages, cultural processes, roles and responsibilities, land, etc. But the most common occurrence of variations of 'restoration' is used in conjunction with 'justice'. Restorative justice has its roots in indigenous traditions (Zehr, 2015, p.5), with Immarigeon \& Daly (1997, p.2) linking its genesis to more widespread practice in the civil rights movements in the United States and concerns by Native and African Americans and feminists to redress imbalances in the justice system. Here we are less concerned with the specifics of restorative justice, although the principles of honouring, valuing and seeking to restore what has been displaced, are central to our work with Aboriginal and Torres Strait Islander peoples. However, even that purpose must be tempered by the acknowledgement that, while Aboriginal and Torres Strait Islander peoples and other indigenous peoples do indeed have a right to have their ways of being, doing and knowing restored, they also should not be constructed as without agency in their own lives. There is a danger in, again, deflecting indigenous authority and capacity for their own development to that of supplicant or recipient of non-indigenous people's beneficence and good will. This somewhat reflects one of the founding realisations of critical race theory that 'the interest of blacks in achieving racial equality will be accommodated only when it converges with the interests of whites' (Bell, 1980, p.523 emphasis added). In our work with Aboriginal and Torres Strait Islander peoples, it is important for us to not impose our constructions of restoration and what that might include.

Restoration is not only giving back or redressing, and Fanon (1967) alerts us to his recurring theme of being human together as the essential ingredient. Maldonado-Torres interprets Fanon's Black Skin, White Masks, (2007, p.260) as describing restoration as decolonisation. Fanon's penultimate sentence is the call for what Maldonado-Torres conceptualises receptive generosity (2008), or the 'restoration of the logic of the gift' (Maldonado-Torres, 2007, p.260). Fanon's own words invite reciprocity as the road to a decolonised future: 'At 
the conclusion of this study, I want the world to recognize, with me, the open door of every consciousness' (Fanon, 1967, p.232).

The restorative purpose and practice, then, is where the activities and actions of recognition and reconciliation come together and where Ally Work may contribute. Restoration is present in the interpersonal as well as in the public spheres, starting for the individual as the politics of recognition. Ethical practice incorporates personal responsibilities and interpersonal relating in the public action of restoration. Being an ally is to engage in ethical essentials. These include: working with the definitions and purposes of Indigenous peoples at their direction; working on our own liberation; realising and working with the long term nature of the work; realising the importance of small actions; becoming involved in anti-racist activities; realising the importance of service and being a servant; and helping all non-Indigenous people 'pay the rent' (Land, 2015).

We now turn to the teaching and learning environment and describe some of the processes we use to try to encourage the next group of practitioners in their Ally Work.

\section{TEACHING AND LEARNING FOR RESTORATIVE OUTCOMES}

The different universities in which we teach have different approaches to presenting Aboriginal and Torres Strait Islander content and materials, in order to satisfy the professional association's standards for accredited courses. In one university, there exists a stand-alone dedicated core unit on working with Aboriginal and Torres Strait Islander people. In the other a broad cross-disciplinary unit underpins and feeds into other offerings during the course. Both have their strengths and limitations, but in both, students have the opportunity to hear from and engage with Aboriginal and Torres Strait Islander people as experts and knowledge holders.

One of the major drawbacks in presenting material to students is that there are so few Aboriginal and Torres Strait Islander people who are willing and have the capacity and resources to contribute to the learning of students. Most Aboriginal and Torres Strait Islander peoples have been touched in some way by the policies and practices of the past in what has now become known as intergenerational or transgenerational trauma (Atkinson, 2002). Reliving 
past events in the classroom takes an emotional toll, which for some people is unacceptably high. Verging on voyeurism, rather than bearing witness to grief, the listening in class to others' pain can become spectatorship which itself draws emotionally on the teller. As an Indigenous person, Dion (2004, p.56) recognises the

need for "tellings" that will disrupt the "taken for granted way of knowing" about First Nations people that we see produced and reproduced in the school curriculum [at the same time that] ... The stories reflect our (re)membered past and contribute to a discourse that affirms the humanity and agency of Aboriginal people and recognizes our work as active social agents resisting ongoing conditions of injustice.

Skill and vigilant attention is needed to tread that fine line between helping the not-knowers learn and understand and feeding the insatiability of wanting to know at the expense of the teller's mental wellbeing. Students value the testimonials, but educators need to ensure these are not produced at too great a cost.

However, the commonly stated adage 'nothing about us without us' must guide the work so that indigenous knowledge is foregrounded in all ways including in its presentation. For example, a university funded project run in one of our social work schools began with Aboriginal Elders designing, developing and delivering each of its steps. Yarning, or storying, a common way of starting any engagement with Aboriginal and Torres Strait Islander peoples, is used to both model practices of engagement as well as provide the culturally safe space for Elders to share their knowledges in ways they choose. Elders in this project were very clear that they represented only the particular groups to which they belong and generalising their culture to all Aboriginal and Torres Strait Islander groups was inappropriate, which was another learning for the students about ownership and diversity.

An activity in one of the units at one university dedicated to learning about Social Work practice with Aboriginal and Torres Strait Islander peoples, is to construct a community profile. In the finding out about local Aboriginal presences, students often expressed surprise that there were Aboriginal people in places where they had neither expected or believed them to be, much less that there were significant and sacred sites in suburbia. Notions of constructed identity, and who is a 'real' Aboriginal person, coupled with contemporary 
ways of being, surprised students and encouraged them to confront previous knowledge and expectations. Recognition here was of lack of knowledge of the history of policies and practices, but also the realisation that there existed in their experience an invisibility of a vibrant and continuing cultural life which shocked the students.

Lessons of recognition accrue to both non-indigenous teachers and students, for all of us are bade to look inward and recognise our own biases, seek means to address them and respond in more appropriate ways. Not only do students learn, so do the lecturers. 'A' recalls:

The work and reflection on 'self' in this space was particularly important, challenging and very rewarding. Let me illustrate with an example. At times students and staff members would ask a question or make a comment at which I would cringe and feel a need to correct, protect and butt in to reverse what was said. The Elders, however, would gently, genuinely and warmly acknowledge the speaker, the message and connect with what was spoken in a way that the speaker was invited to consider a perspective offered from the lived experience of the Elder. This was done in such a natural way that often the lesson was for myself to pay attention to my self-righteousness. As one student said of the project at the end, "the Elders know what they want to teach us". My privileged positioning and power assigned to role of academic and project leader subliminally invokes an 'expert' knowing of something I'm not in a position to correct.

Acts of recognition also occur with knowing, learning what has not been known before, but now acknowledged as having validity and truth; the realisation of truth rather than it necessarily having previously been known. Such recognitive outcomes are themselves acknowledged by students, and ourselves, as adding to and stimulating a desire to know more, to engage in different ways and to continue a journey towards emancipation. In the words of social worker Lilla Watson:

If you have come to help me you are wasting your time. But if your emancipation is tied to mine then let us work together (acknowledged as having various locational attribution in Young (Watson, 2004, p.118) 
A Maori colleague phrases it such, citing Marley's Redemption Song:

Emancipate yourselves from mental slavery; None but ourselves can free our minds. (Marley, 1980)

From recognition comes the possibilities for reconciliation. The project mentioned above enables relationships to be formed where previously there may have been hesitation on both sides, possible distrust from Aboriginal people who have not always been welcomed into academia and whose relationships with social workers have not always been constructive. Students too have not necessarily been exposed to Aboriginal and Torres Strait Islander peoples as experts, but only as clients. Repositioning these relationships and engendering possibilities for trusting equal engagement is part of a reconciliatory purpose. The Elders reported that they felt respected and valued for their knowledge and sharing of culture by the ways in which staff worked with them and students responded to them. Elders were repositioned from that of Aboriginal person, to a cultural advisor and wisdom holder to be admired and respected. This being human together was a profound realisation for students.

Another unit taught at one of the universities includes school leaders as students. These managers were interested in improving their relationships with the Aboriginal families and Elders in their localities. Part of their chosen activities for the unit was therefore to design processes whereby they could consult with local people to undertake activities of importance to the Aboriginal people. Often these turned out to be Reconciliation Action Plans (RAPs) with some considerable and on-going success for the schools and the local communities.

Structural reconciliation also occurred in the above mentioned project, with the administrative structures in the university being made aware of the inequities of university systems. Elders' expertise is not academic and so does not immediately appear in the usual schedule of pay rates for work undertaken. The accounting systems also tend to work according to business procedures of monthly payment schedules. Neither of these are suited to the lives and experiences of people not in the formal and secure workforce. Advocating for changes to better acknowledge the life circumstances of the Elders resulted in changes to the university systems.

One of the critical outcomes of the project was for the Elders themselves. They reported, at the conclusion of the project, that they had gained confi- 
dence in their interactions with other non-indigenous people and were more willing to initiate conversation with previously unknown people, ask questions of non-indigenous service providers such as general practitioners, and engage with students' own honest concerns without judgement or anger. Future relationships, previously not considered possible, began to become realistic. Confidence, too for the students, was increased. One student retold of approaching a stall at a festival staffed by Aboriginal people where previously discomfort would have prevented this interaction. The Elders had instilled this confidence in the student to start to pursue these types of interactions, out of which may come further relationships.

These outcomes from the opportunities offered in the teaching environment are also extended beyond into practice. One example is of a student who sought to undertake a placement in an Aboriginal agency because of the interest developed during the teaching in class. Following this successful placement, this student then enquired about undertaking a second placement in Aotearoa New Zealand specifically with indigenous people from that place. This placement too was a success, despite the student not having a background in Maori language and Treaty knowledge, expected of New Zealand students. Eventually the student was offered and accepted a position working in a Maori agency. The student found both placement agencies challenging and the work confronting but, without conceptualising it as such, epitomised what we would call Ally Work, itself recognised by the local indigenous people.

External practice may also occur while students are still students, with some returning to the classroom telling of experiences of challenging racism. One student witnessed young Aboriginal girls in a shopping centre having their bags checked by security guards, and asked whether the guards would routinely check the bags of non-Aboriginal teenagers. Another arranged a welcome to the country in a workplace, where previously this had not been done. Another told of an incident on placement where the supervisor spent more time than was expected at the home of an Aboriginal client and apologised for keeping the student after hours. The student responded with the understanding that this time was valuable in helping to build the relationships rather than meeting the deadlines set by the agency. From the learnings in class and interactions with Aboriginal people, students have been much more willing to embrace practices that acknowledge Aboriginal ways of being, doing and knowing. This bodes well for future practice. 
Many students in both universities state that they want to continue to be involved, to keep up to date, to continue learning. Aboriginal and Torres Strait Islander colleagues tell us how impressed they are with the graduates and their engagement with Aboriginal and Torres Strait Islander matters, and particularly their ability to form good working relationships. We take this less as commendations of our teaching and more of the exposure we have been privileged to offer to students to Aboriginal and Torres Strait Islander peoples.

\section{ALLY WORK IN SOCIAL WORK EDUCATION}

The need for practitioners who are able to work effectively with Indigenous peoples and with Aboriginal and Torres Strait Islander peoples in Australia as a particular group of indigenous peoples, has been variously conceptualised as being able to be met through becoming culturally aware or sensitive (Hollinsworth, 1992), acquiring cultural competence (Herring, Spangaro, Lauw, \& McNamara, 2013), providing cultural security (Downing, Kowal, \& Paradies, 2011), and becoming culturally responsive (Young et. al., 2013). We add to these concepts by adapting Canadian Bishop's commendation to 'become an ally' (Bishop, 2002). Since then Land (2015), writing of the Australian experience, has discussed the dilemmas of being an ally and offered ways to resolve some of these. Both these works, as well as others, have informed our work and our framework for practice, presented here, in which we seek to be allies as well as encourage our students to develop their ways of working collaboratively and productively with Aboriginal and Torres Strait Islander (in particular) peoples in whatever forms they consider appropriate for them.

The Ally Work framework is the latest iteration of our reflections on our practice inside and outside the social work classroom. It serves a current purpose of explaining what we do and how we consider our classroom activities, and their outcomes may serve the aims of contributing to reconciliation, in addition to also providing its theoretical underpinnings in other writing (Hendrick \& Young, 2018). While this framework is a recent development, it has its genesis in experiences over some 40 and 20 years respectively, which indicate the need to attend more assiduously to what Aboriginal and Torres Strait Islander people were trying to tell service providers about how they wanted to be treated, pleas made through language and action, many of which were ignored or not understood. It took some years and many mistakes to fully 
realise what was being communicated, and subsequent actions and statements by our students reinforced the imperative to try to be clear about what needed to be done and how. It is not claimed here that we have solved the issue of providing appropriate and relevant services to Indigenous peoples, for we have not. What we have done is to try to formulate a way that explains what we want to do and how, in order to encourage the development of more effective working in the 'third space' (Ikas \&Wagner, 2008). It is this that we present to students to illustrate our work and to encourage them to frame their work in ways that is meaningful to them. Figure 2 summarises our conceptualisations of how this working in the 'third space' may be pictorially represented.

Figure 2. The practices of Ally Work

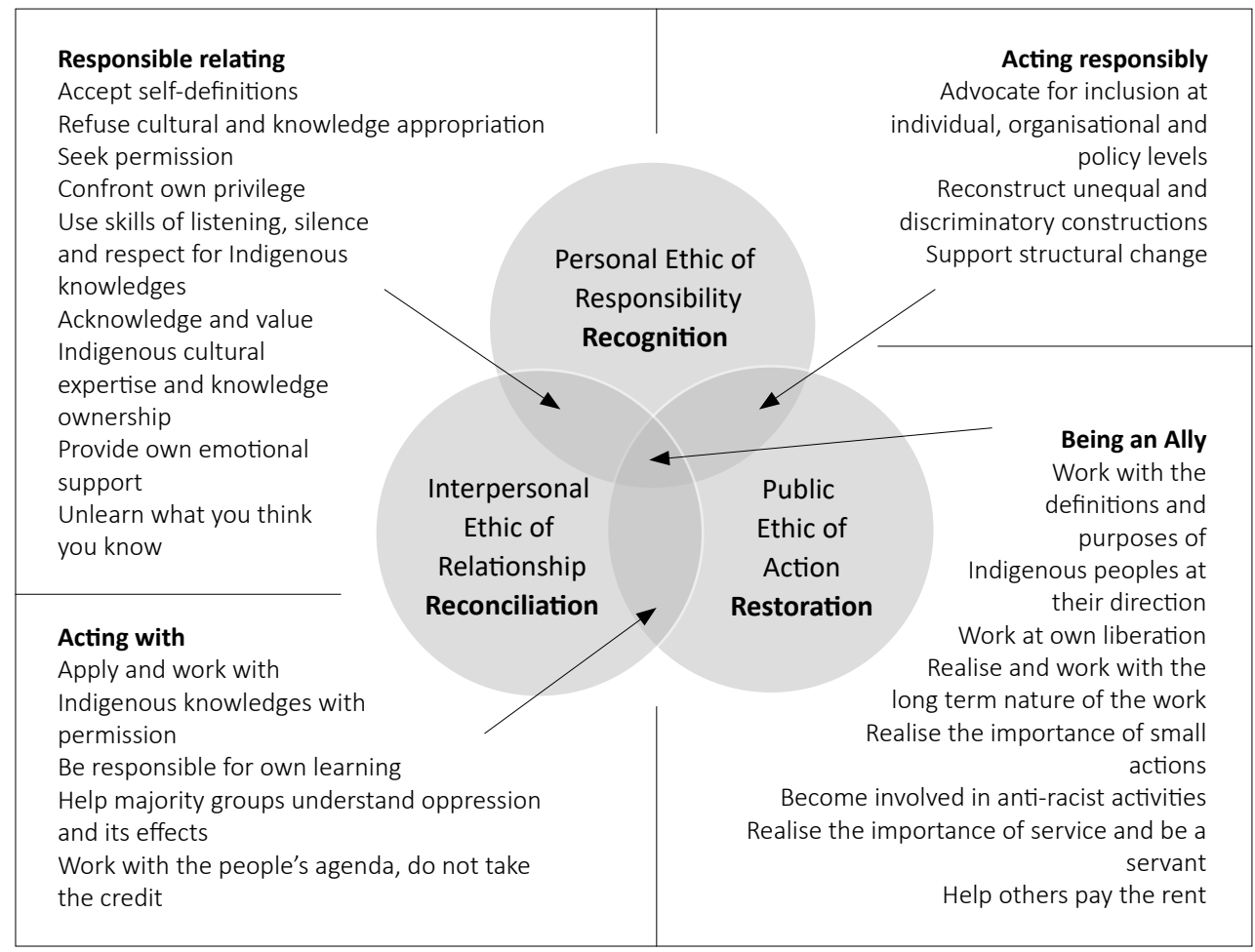

Based on the Ally Work Framework (Hendrick \& Young, 2017) 
We have explained above that a foundation for us is ethical practice of the self, and in relations with others both at an individual and public level. These relationships, responsibilities and actions bring together practices founded on principles that together contribute to working alongside Aboriginal and Torres Strait Islander peoples in ways that draw on the skills and knowledges we possess, and on using these as resources rather than as imperatives and directives. There are some key principles, such as always seeking permission, and acknowledging the legitimacy of indigenous ways of knowing, being and doing, among others. There are also key actions and activities to be undertaken, such as using the skill of listening deeply in order to hear. A critical skill and activity for an ally is to be critically self-reflective and willing to confront the privilege that continues to impact on the relationships with indigenous peoples. Another important task is to assist members of the majority group, often our own, to themselves become allies, or to learn the skills and mechanisms of inclusion and anti-discrimination. All these practices are core elements of the social work curriculum, along with exposure to and development of skills and knowledges of social justice, human rights and commitment to social work values and ethics (IASSW, 2004). These are expected to be taught so that social work graduates may meet the required international standards. Even so, a study conducted in 2012/3 found that only a very few of the social work schools in Australia had staff who reported they felt confident and well equipped to teach Aboriginal and Torres Strait Islander content and materials (Bessarab et. al., 2016). It is a continuing task for all social work educators in Australia, to which we offer this contribution.

Nevertheless, it is also recognised that this work is not without its challenges, amongst which is the potential for structural and interpersonal resistance, some of which are addressed above. Walter and Baltra-Ulloa (2019) describe the many other resistances that present in response to educators confronting what they, following DiAngelo (2018), characterise as white fragility. Ally work runs similar risks including less active resistances than those described by Walter and Baltra-Ulloa. White fatigue (Flynn, 2015), white discomfort (Zembylas, 2018) and the disconnected power-analysis frame (Jayakumar \& Adamian, 2017) are just some of the recent ways authors seek to understand how students in particular react to educational strategies, encouraging them to engage in the very difficult endeavour of turning the spotlight away from the racial 'other' to the racial self (which represents the majority group), in this case the white Australian. Notwithstanding the very multi- 
cultural composition of Australia, replicated in our classrooms, those who are Australian by birth or with several generations of inhabitancy and those from Culturally and Linguistically Diverse backgrounds, who do not identify as Aboriginal and Torres Strait Islander peoples are standing on stolen land. The recognitive, reconciliary, restorative strategies incorporated in such frameworks as Ally work are directed towards redressing, in some way, the injuries of the past which indeed continue into the present. Imperfect and small scale as it may be, an Ally framework for us is one, but not the only, way forward.

The focus for our Ally work is not those people who themselves are not 'white', but those who are the First Nations of this land, which complicates the discussion about whiteness. This, nonetheless, implicates all those people who do not have Aboriginal and Torres Strait Islander heritage. As discussed in the early pages of this chapter, identity and identifying are complex matters, threatening to descend into binaries resulting in the 'us' and 'them' of a racial divide. While this chapter does not seek to offer a definitive answer to both the problematic of the 'either-or' or the way to avoid the risks of presenting Ally work, some of our experiences described above and in other writings (Hendrick \& Young, 2017: 2018) show how we have dealt with some of these resistances both at the interpersonal and the structural levels.

The structural embodiment of colonial heritage in Australia presents additional challenges, even at the same time as the University collectivity recognises the need for better engagement with and service toward Aboriginal and Torres Strait Islander peoples (Universities Australia, 2011). Bunda (2018) and Gilbey \& McCormak (2017) describe these in the Australian setting. They catalogue, to some extent, similar instances of institutional resistances as we describe above, as well as some of the more extensive systemic intransigencies. These include failing to acknowledge different ways of knowing being and doing, failing to ensure the educational environment is a safe space for Aboriginal and Torres Strait Islander students and lecturers, and effectively sidelining Aboriginal and Torres Strait Islander knowledges as legitimate and equal knowledge systems. Identifying these systems and practices as examples of White privilege, Walter and Baltra-Ulloa charge educators to 'unveil' Whiteness and commit to practices of race-visibility (Walter \& Baltra-Ulloa, 2019). While practical matters such as altering the teaching/learning spaces with their fixed classrooms present difficulties, the less visible practices will need greater attention. We hope that Ally work is a small step towards race-visibility. 


\section{CONCLUSION}

In a settler nation such as Australia, where the First Nations peoples will never comprise more than the non-indigenous population, and where they are sadly likely in the near term to at least be in the majority of the social work clientele, the teaching and learning environment will never be fully decolonised. In developing a framework for practice for ourselves, we hope to both continue to unsettle colonising practices and contribute to a structural and relational reconciliation which incorporates fully human relationships. We hope our students will continue their efforts to frame their work in productive, recognitive, reconciliatory and restorative ways. Through this and others' work, we hope for educative practices that are Aboriginal and Torres Strait Islander designed, developed, and delivered. Despite the ongoing retreat on so many fronts by governments and social policy makers, the Academy should not replicate those nor relax vigilance. The restorative project is never more important than it is now. 


\section{REFERENCES}

Absolon, K. E. (2016). Wholistic and ethical: Social inclusion with indigenous peoples. Social Inclusion, 4(1). https://doi.org/10.17645/si.v4i1.444

Atkinson, J. (2002). Trauma trails, recreating song lines: The transgenerational effects of trauma in Indigenous Australia. Melbourne: Spinifex Press.

Bay, U. (2014). Social work practice: a conceptual framework. South Yarra, Melbourne: Palgrave Macmillan.

Bell, D. A. (1980). Brown v. Board of Education and the Interest-Convergence Dilemma. Harvard Law Review, 93(3), 518-533.

https://doi.org/10.2307/1340546

Bessarab, D., Green, S., Zubrzycki, J., Jones, V., Stratton, K., \& Young, S. (2016).

Getting it right: Aboriginal and Torres Strait Islander knowledge and practices in Australian social work education. In M. A. Hart, A. Burton, \& K. Hart (Eds.), International Indigenous Voices in Social Work (p. 133-147). Cambridge Scholars Publishing.

Bhabha, H. K. (1994). The Location of Culture. London and New York: Routledge.

Bishop, A. (2002). Becoming an Ally: breaking the cycle of oppression (2 ed.). Crows Nest, NSW: Allen \& Unwin.

Bunda, T. (2018). The raced space of learning and teaching. The relationality of race in education research. G. Vass, J. Maxwell, S. Rudolph \& K.N.Gulson (eds) The Relationality of Race in Education Research (p. 85-96). New York: Routledge. https://doi.org/10.4324/9781315144146-7

Chow, R., M, \& Knowles, E., D. (2015). Taking Race Off the Table: Agenda Setting and Support for Color-Blind Public Policy. Personality and Social Psychology Bulletin, 42(1), 25-39. https://doi.org/10.1177/0146167215611637

DiAngelo, R. (2018). White fragility: Why it's so hard for white people to talk about racism. Boston: Beacon Press.

Dion, S. D. (2004). (Re) telling to disrupt: Aboriginal people and stories of Canadian history. Journal of the Canadian Association for Curriculum Studies, 2(1).

Downing, R., Kowal, E., \& Paradies, Y. (2011). Indigenous cultural training for health workers in Australia. International Journal for Quality in Health Care, 23(3), 247-257. https://doi.org/10.1093/intqhc/mzr008

Dudgeon, P., \& Pickett, H. (2000). Psychology and Reconciliation: Australian Perspectives. Australian Psychologist, 35(2), 82-87.

https://doi.org/10.1080/00050060008260328 
Fanon. (1967[1952]). Black skin, white masks. Grove Press: New York.

Flynn, J. E. (2015). White Fatigue: Naming the Challenge in Moving from an Individual to a Systemic Understanding of Racism. Multicultural Perspectives, 17(3), 115-124. https://doi.org/10.1080/15210960.2015.1048341

Gavrielides, T., \& Artinopoulou, V. (2016). Reconstructing restorative justice philosophy. Oxon, New York: Routledge. https://doi.org/10.4324/9781315604053

Gilbey, K., \& McCormack, R. (2017). The two years that killed a First Nations University. In The relationality of race in education research (p. 132-144). Routledge. https://doi.org/10.4324/9781315144146-11

Graeme, C. S., \& Mandawe, E. (2017). Indigenous geographies: Research as reconciliation. International Indigenous Policy Journal, 8(2); Retrieved from: https://ir.lib.uwo.ca/iipj/vol8/iss2/2. https://doi.org/10.18584/iipj.2017.8.2.2

Hendrick, A., \& Young, S. (2017). Decolonising the Curriculum, Decolonising Ourselves: Experiences of Teaching in and from the 'Third Space'. Advances in Social Work and Social Welfare Education, 19(2), 9-24.

Hendrick, A., \& Young, S. (2018). Teaching about decoloniality: the experience of non-Indigenous social work educators. American Journal of Community Psychology, 0, 1-13. https://doi.org/10.1002/ajcp.12285

Herring, S., Spangaro, J., Lauw, M., \& McNamara, L. (2013). The Intersection of Trauma, Racism, and Cultural Competence in Effective Work with Aboriginal People: Waiting for Trust. Australian Social Work, 66(1), 104-117. https://doi.org/10.1080/0312407X.2012.697566

Hollinsworth, D. (1992). Cultural awareness training, racism: awareness training or antiracism? strategies for combating institutional racism. Journal of Intercultural Studies, 13(2), 37-52. https://doi.org/10.1080/07256868.1992.9963389

IASSW. (2004). Global standards for the education and training of the social work profession. Retrieved from http://cdn.ifsw.org/assets/ifsw_65044-3.pdf Ikas, K., \& Wagner, G. (2008). Communicating in the third space (Vol. 18). London: Taylor \& Frances. https://doi.org/10.4324/9780203891162

Immarigeon, R., \& Daly, K. (1997). Restorative justice: Origins, practices, contexts, and challenges. The ICCA Journal on Community Corrections, 8(2), 13-19.

Jayakumar, U. M., \& Adamian, A. S. (2017). The fifth frame of colorblind ideology: Maintaining the comforts of colorblindness in the context of white fragility. Sociological Perspectives, 60(5), 912-936. https://doi.org/10.1177/0731121417721910 
Krieken, R. V. (1999). The stolen generations' and cultural genocide: The forced removal of Australian Indigenous children from their families and its implications for the sociology of childhood. Childhood, 6(3), 297-311. https://doi.org/10.1177/0907568299006003002

Land, C. (2015). Decolonizing solidarity: Dilemmas and directions for supporters of indigenous struggles. Zed Books Ltd.

Lu, C. (2018). Reconciliation and Reparations. In S. Lazar \& H Frowe (Eds), The Oxford Handbook of Ethics of War. Oxford University Press.

Maldonado-Torres, N. (2007). On the Coloniality of Being: Contributions to the Development of a Concept. Cultural studies, 21(2-3), 240-270. https://doi.org/10.1080/09502380601162548

Maldonado-Torres, N. (2016). Outline of Ten Theses on Coloniality and Decoloniality. Retrieved from http://caribbeanstudiesassociation.org/docs/MaldonadoTorres_Outline_Ten_Theses-10.23.16.pdf [20/10/18] Maldonado Torres, N. (2008). Against War: Views from the Underside of Modernity. Durham: Duke University Press. https://doi.org/10.1215/9780822388999 Marley, B. (1980). Redemption Song. On Uprising.

Mulcock, J. (2007). Dreaming the circle: indigeneity and the longing for belonging in White Australia. Transgressions: Critical Australian Indigenous Histories, 16, 63. https://doi.org/10.22459/T.12.2007.04

Nadler, A. (2012). Intergroup reconciliation: Definitions, processes, and future directions. Oxford library of psychology. The Oxford handbook of intergroup conflict, 291-308. https://doi.org/10.1093/oxfordhb/9780199747672.013.0017

Riggs, D. W. (2005). Benevolence, belonging and the repression of white violence. Retrieved from https://digital.library.adelaide.edu.au/dspace/ bitstream/2440/37755/9/01front.pdf

Sandoval, C. (2000). Methodology of the Oppressed. Minneapolis: University of Minnesota Press.

Truth and Reconciliation Commission, S. A. (1998). Truth and Reconciliation Commission Final Report. Retrieved from http://www.justice.gov.za/trc/report Universities Australia. (2011). Guiding principles for developing Indigenous cultural competency in Australian Universities. Canberra: Universities Australia.

van den Berg, R. (2004). Missions, Settlements and the Stolen Generations. AustLit. Walter, M., \& Baltra-Ulloa, J. (2019). Australian social work is white. In B.

Bennett \& S. Green (Eds.), Our voices. Aboriginal social work ( $2^{\text {nd }}$ ed.). London: Red Globe Press. 
Young, S. (2004). Social work theory and practice: the invisibility of whiteness. In A. Moreton-Robinson (Ed.), Whitening race: essays in social and cultural criticism (p. 104-118). Canberra: Aboriginal Studies Press.

Young, S., Zubrzycki, J., Bessarab, D., Green, S., Jones, V., \& Stratton, K. (2013). 'Getting it Right: Creating partnerships for change': developing a framework for integrating Aboriginal and Torres Strait Islander knowledges in Australian social work education. Journal of Ethnic And Cultural Diversity in Social Work, 22(3-4), 179-197. https://doi.org/10.1080/15313204.2013.843120

Zehr, H. (2015). The little book of restorative justice: revised and updated. Skyhorse Publishing, Inc.

Zembylas, M. (2018). Affect, race, and white discomfort in schooling: decolonial strategies for 'pedagogies of discomfort'. Ethics and Education, 13(1), 86-104. https://doi.org/10.1080/17449642.2018.1428714

Zubrzycki, J., Green, S., Jones, V., Stratton, K., Young, S., \& Bessarab, D. (2014). Getting it right. Creating partnerships for change. Integrating Aboriginal and Torres Strait Islander knowledges in social work education. Teaching and learning framerwork (A. G. O. o. L. a. Teaching Ed.). Sydney: Australian Government Office of Learning and Teaching. 